\title{
Baroreflex modulation of ventricular rhythm in atrial fibrillation
}

\author{
C. Borst* AND F. L. MeIJLER $\dagger$ \\ *Department of Physiology, University of Amsterdam, Amsterdam, and $\uparrow$ Department of Cardiology, \\ University Hospital Utrecht, Utrecht, The Netherlands
}

KEY WORDS: Atrial fibrillation, baroreceptor reflex, atrioventricular conduction.

The influence of bilateral carotid sinus nerve stimulation was studied in a patient with atrial fibrillation. Stimulation resulted after approximately $1.5 \mathrm{~s}$ in abrupt prolongation of the minimum, median and maximum RR-interval, and in greater RR-interval dispersion. Virtually no change was observed in the random character of the ventricular rhythm. The absence of demonstrable baroreflex modulation of the ventricular rhythm in atrial fibrillation is probably due to the relatively long latency of the reflex effect on atrioventricular conduction in relation to the duration of the RR-intervals.

\section{Introduction}

From 1965 to the early seventies, bilateral electrical stimulation of the carotid sinus nerves (CSN) has been used in the treatment of refractory hypertension $^{[1,2]}$, angina pectoris ${ }^{[2,3]}$ and supraventricular tachycardia ${ }^{[4]}$. In the treatment of hypertension the stimulation device continuously activates baroreceptor afferent fibres in the carotid sinus nerves.

We report a patient with chronic atrial fibrillation and a high ventricular rate in whom electrical stimulation of the carotid sinus nerves lowered ventricular rate significantly. The main feature of the ventricular rhythm in atrial fibrillation is its absolute irregularity or random pattern ${ }^{[5,6]}$. The effect of autonomic nervous control on atrioventricular conduction and/or atrial electrical behaviour during atrial fibrillation is still ill understood. The presentation of this unique case may shed some light on this problem.

\section{Methods}

A 51-year-old man was examined 17 months after implantation of a carotid sinus nerve stimulator (Barostat ${ }^{\circledR}$, Medtronic), in order to establish

Received for publication on 16 March 1984 and in revised form 20 August 1984.

Address for correspondence and reprints: Dr C. Borst, University Hospital Utrecht, Department of Cardiology, Catharijnesingel 101, 3511 GV Utrecht, The Netherlands. optimal stimulus parameters ${ }^{[7]}$ in the treatment of severe hypertension ${ }^{[1]}$ that was refractory to medication. The measurements were performed after informed consent had been obtained. No hospital ethical committee had been instituted at the time of the study.

\section{CAROTID SINUS NERVE STIMULATION}

Carotid sinus nerve (CSN) stimulation was applied as described elsewhere ${ }^{[8,9]}$. Briefly, a modified Medtronic transmitter produced an amplitude modulated radiofrequency wave that was transmitted with an antenna coil taped on the skin overlying the receiver. The stimulus pulses were generated in the subcutaneous receiver and delivered bilaterally to the electrodes around the carotid sinus nerves. The pulse width was 0.35 or $2.0 \mathrm{~ms}$, the frequency was 20 to $100 \mathrm{~Hz}$ and the stimulus intensity was 3 or $2 \mathrm{~V}$, depending on the pulse width (the intensity was estimated from calibration in vitro, the in vivo voltage was imprecisely known due to the nature of the device ${ }^{[9]}$ ). The stimulation device was activated 16 times for periods of $90 \mathrm{~s}$. Two min elapsed between stimulation runs. In addition to chronic continuous CSN stimulation, the patient was treated with reserpine, dihydrochlorothiazide, chlorothiazide and digoxin. These drugs were not interrupted because of the severity of the hypertension.

\section{MEASUREMENTS}

The electrocardiogram was recorded from bipolar chest leads. Blood pressure was measured 
in the axillary artery (P23Db transducer, Statham) and respiration was monitored with a thermistor in one nostril. Together with the stimulus pulses, these signals were written on a polygraph and stored on an instrumentation recorder (FR 1300, Ampex) for later analysis with a digital computer (PDP 11/40, Digital Equipment Corporation) ${ }^{[9]}$. The ventricular rhythm was analysed with and without CSN stimulation by means of the histogram, the joint-interval distribution and the serial autocorrelogram of the recorded RR-intervals $^{[10]}$. A histogram reveals the average rates of the $\mathrm{R}$ waves and the distribution of the RR-interval durations. The joint interval distribution -demonstrates the relationship between the durations of directly succeeding RR-intervals; e.g. RRinterval 1 with 2, RR-interval 33 with 34 and RR, interval $n$ with $(n+1)$. The serial autocorrelogram (SAC) provides information about the presence or absence of a mutual relationship between all recorded RR-intervals.

EXPLANATION OF RR-INTERVAL SAC

Suppose 1000 successive recorded RR-intervals and the durations of all these RR-intervals have been measured in ms. Firstly, one can correlate each interval with itself. This will result in a correlation coefficient of 1 . Next, one can correlate interval 1 with 2,2 with 3 and $n$ with $(n+1)$. In case of no mutual relationship the correlation coefficient will be about 0 . After this, RR-interval 1 can be correlated with 3,2 with 4,3 with 5 , n with $(n+2)$ etc. In the absence of any relation between this two sets of RR-interval durations, again the correlation coefficient will be 0 . So we may proceed until for instance each RR-interval (n) is correlated with RR-interval ( $n+1$ up to 20 ). This will provide 21 successive correlation coefficients. Correlation coefficient 0 represents the correlation between each RR-interval with itself. Correlation coefficient 1 represents the correlation between each RR-interval with the next, etc. The k-th correlation coefficient is a measure for the relation between all RR-intervals that are $\mathrm{k}$ intervals apart. These correlation coefficients are dimensionless and have values between -1 and +1 . All these correlation coefficients can be listed, ranging from 0 till 20 and plotted against the value of the correlation coefficient. This provides a serial correlogram. When a phenomenon is correlated with itself, as in the present case, one RR-interval duration with another RR-interval duration, the serial correlogram is called a serial autocorrelogram
(SAC). If for instance RR-interval durations are correlated with left ventricular peak-pressure values it would be called a serial crosscorrelogram. Computation of serial correlograms is nowadays a standard procedure to describe all kinds of phenomena in biology and physics, for further mathematical details see ref. ${ }^{[10]}$.

If in a RR-interval SAC of a patient with atrial fibrillation; with the exception of correlation coefficient 0 , which by definition equals +1 ; all (further) coefficients have a value of about 0 , the rhythm is called random. If the values of all or a number of successive correlation coefficients differ from 0 then a certain pattern in the rhythm has to be present. So a SAC provides quantitative information about the sequential behaviour of RR-intervals within a ventricular rhythm. The technique can be applied to describe any kind of rhythm.

\section{STATISTICAL ANALYSIS}

Statistical analysis was performed with the Wilcoxon signed rank test. $P<0 \cdot 05$ was considered to indicate a significant difference.

\section{Results}

Mean ventricular rate increased from about 80 to $150 \mathrm{~min}^{-1}$ when the permanently active CSN stimulator of the patient was disconnected. Mean arterial pressure increased from about 150 to $170 \mathrm{mmHg}$. Evidently, chronic CSN stimulation slows the ventricular rhythm as long as the CSN stimulation is continued. Fig. 1 shows an example of the abrupt RR-interval prolongation when CSN stimulation was resumed. The increased respiratory rate suggests that some chemoreceptor fibres in the carotid sinus nerves were stimulated as well ${ }^{[2]}$.

The RR-intervals in the $30 \mathrm{~s}$ prior to the start of stimulation differed greatly from the RR-intervals in the last $60 \mathrm{~s}$ of the $90 \mathrm{~s}$ stimulation period. Depending on the stimulus parameters ${ }^{[9]}$, both the minimum, mean, median and maximum RRinterval increased with CSN stimulation, as well as the RR-interval dispersion. This is illustrated by Figs 1 and 3.

\section{SERIAL AUTOCORRELOGRAM}

In contrast to the considerable difference in rate, the average of 16 SACs of the RR-intervals was virtually similar with and without CSN stimulation (Fig. 2). Without carotid sinus nerve stimulation, 

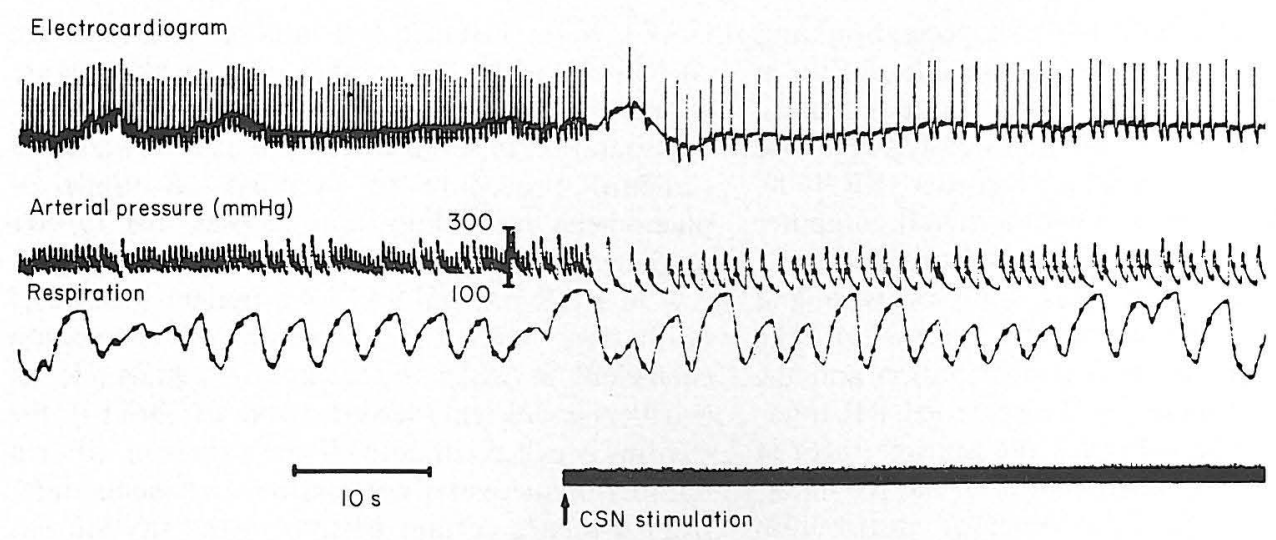

Figure 1 Cardiovascular effects evoked by bilateral electrical stimulation of the carotid sinus nerves $(0.35 \mathrm{~ms} ; 100 \mathrm{~Hz} ; 3 \mathrm{~V})$ in a hypertensive patient with chronic atrial fibrillation. Respiratory signal is from a thermistor in a nostril, inspiration downwards ( $\mathrm{CSN}=$ carotid sinus nerve).

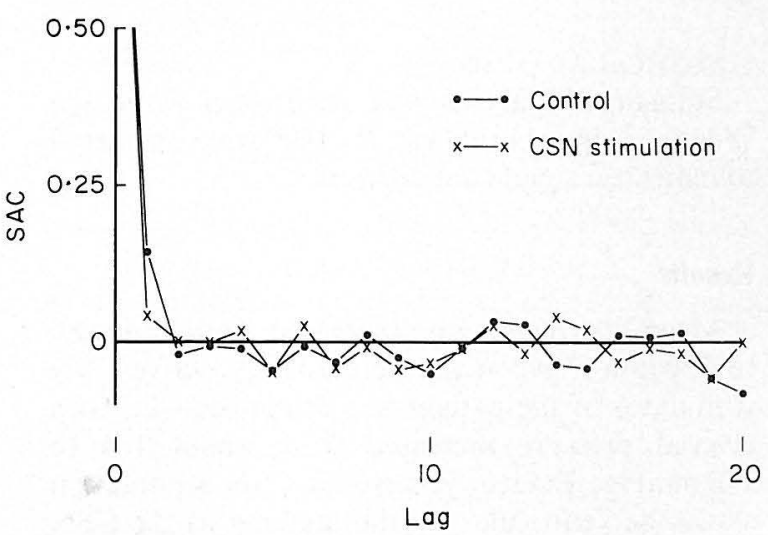

Figure 2 Average $(\mathrm{N}=16)$ serial autocorrelogram of RR-intervals before $(O)$ and during carotid sinus nerve stimulation (x). Mean ventricular rate dropped from $150 \mathrm{~min}^{-1}$ to below $100 \mathrm{~min}^{-1}$ during stimulation (SAC $=$ serial autocorrelation coefficient; $\mathrm{Lag}=$ coefficient number; $\mathrm{CSN}=$ carotid sinus nerve).

thus at a high average ventricular rate, the mean first coefficient $(0 \cdot 145)$ was only slightly positive $(P<0 \cdot 01)$. The second and higher order coefficients (up to 20) did not differ from zero. During CSN stimulation the 1 st correlation coefficient diminished to 0.045 which was not significantly different from zero. As already pointed out a SAC with coefficients that do not differ from zero indicates that there is no relation between the successive RR-intervals. In this case the maximum computed lag or number of computed correlation coefficients was 20 .

\section{JOINT-INTERVAL DISTRIBUTION}

The scatter plot of the (n)th RR-interval vs the $(n+1)$ th RR-interval (Fig. 3) indicates that the slightly positive first autocorrelation coefficient in the SAC, found only in the absence of stimulation, is due to RR-intervals of less than approximately $400 \mathrm{~ms}$ duration. These short intervals tended to cluster around the line of identity. Longer RRintervals did not show this tendency. During CSN stimulation few RR-intervals of less than $400 \mathrm{~ms}$ were present.

\section{Discussion}

This case report presents the first demonstration of abrupt slowing of the ventricular rhythm produced by electrical stimulation of the carotid sinus nerves in a patient with atrial fibrillation. The substantial increase in mean ventricular rate upon disconnecting the stimulator indicates that indeed it is the chronic CSN stimulation, applied for the treatment of hypertension, that slows the ventricular rhythm as long as the stimulation is being applied.

\section{AUTONOMIC INFLUENCE ON ATRIOVENTRICULAR} CONDUCTION

The reflex negative effect of carotid sinus nerve stimulation $^{[4,8]}$ on AV conduction is probably confined to the atrioventricular node, because conduction in the specialized ventricular conduction system has been reported to remain unchanged with direct ${ }^{[11]}$ or reflex ${ }^{[8,12]}$ changes in autonomic tone. In addition, it has been established, that the distal part of the specialized conduction system 


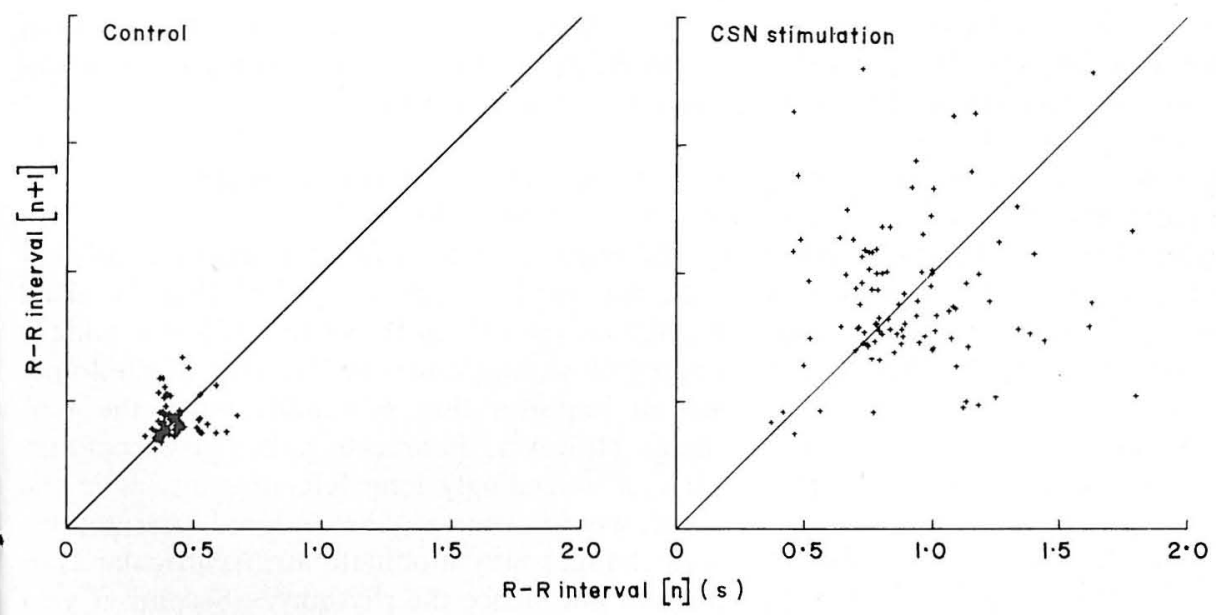

Figure 3 Joint-interval distribution of the RR-intervals before (left) and during (right) carotid sinus nerve stimulation $(0.35 \mathrm{~ms} ; 100 \mathrm{~Hz} ; 3 \mathrm{~V}$; last $60 \mathrm{~s}$ of $90 \mathrm{~s}$ stimulation run). The solid line is the line of identity $(\mathrm{CSN}=$ carotid sinus nerve $)$.

does not influence the ventricular irregularity in atrial fibrillation ${ }^{[13]}$.

The slowing effect of augmented baroreceptor afferent activity on atrio-ventricular conduction is mediated primarily by the reflex augmentation of cardiac vagal tone, but inhibition of sympathetic tone has been found as well ${ }^{[8,12]}$. The abrupt RR-interval prolongation as shown in Fig. 1 also suggests that the reflex effect was predominantly of parasympathetic origin ${ }^{[8,14]}$. This may explain why the antihypertensive drugs did not affect the large stimulus response to any major extent.

\section{COMPARISON WITH DIGITALIS}

The similar influence of digitalis on the ventricular rhythm in atrial fibrillation ${ }^{[10]}$ may be attributed to comparable changes in autonomic tone to the heart ${ }^{[15]}$ caused reflexly by the acti-

- vating influence of digitalis on baroreceptors ${ }^{[16,17]}$.

As we outlined in one of our first papers on this subject ${ }^{[10]}$, digitalis may increase the number of atrial impulses that reaches the AV junction in a given unit of time. This increase in number of atrial excitation waves causes an increase in concealed conduction and thus a prolongation of median and maximum RR-intervals. The prolongation of the minimum RR-intervals can be attributed to the increase in the functional refractory period (FRP) of the AV node ${ }^{[18]}$. In this respect CSN stimulation exhibits the same effect as digitalis. Their mode of action, however, may not be identical. This is exemplified by the discrepancy between digitalis and CSN stimulation in their respective effect on sinus rate in patients without heart failure. CSN stimulation slows the sinus rate ${ }^{[7-9]}$, whereas digitalis produces no or only insignificant changes in sinus rate in the absence of heart failure ${ }^{[19]}$.

MacKenzie ${ }^{[5]}$ demonstrated that digitalis in patients with mitral stenosis and sinus rhythm did not significantly slow heart rate, whereas in patients with mitral stenosis and atrial fibrillation the heart (ventricular) rate dropped dramatically. It therefore may be concluded that the effect of CSN stimulation in atrial fibrillation is most likely of parasympathetic origin, whereas the digitalis effect may or may not be or only partially be due to vagal activity. Despite the fact that the digitalis effect in atrial fibrillation is inhibited by atropine, there is no conclusive evidence that digitalis acts via the vagus nerves. Its direct effect on atrial fibers would suffice to explain its major action ${ }^{[20]}$.

In this particular case, CSN stimulation and digitalis may have worked synergistically. However, the high ventricular rate without CSN stimulation suggests that digoxin was given in too low a dose or that absorption was poor. Digoxin plasma levels are not available. In a recent paper we discussed also the action of other drugs such as amiodarone, quinidine and verapamil in atrial fibrillation $^{[21]}$. It can be assumed that at least part of the effect of a drug with an influence on the ventricular rate in atrial fibrillation is mediated through its influence on the atrial myocardium. Prolongation of the functional refractory period 
of the AV conduction system cannot solely explain why the ventricular rate becomes more regular on verapamil or why the duration of long RRintervals increases during digitalis. In this particular case the decrease in ventricular rate is associated with an increase in RR-interval dispersion. This is in agreement with Billette's observations $^{[22]}$. However, we found that in dogs with spontaneous atrial fibrillation and higher mean ventricular rates than in human subjects, the $\mathrm{RR}$-interval dispersion is not smaller ${ }^{[21]}$. Also verapamil that has a slowing effect on ventricular rate in atrial fibrillation diminishes RR-interval dispersion $^{[23,24]}$.

In conclusion: there are no simple rules to explain the effect of CSN stimulation or drug action in patients with atrial fibrillation, nor can the relation between ventricular rate and RR-interval dispersion be easily predicted.

\section{LATENCY OF BAROREFLEX EFFECT ON}

ATRIOVENTRICULAR CONDUCTION

The estimated $1.5 \mathrm{~s}$ latency of the reflex response (Fig. 1) corresponds to the upper limit of a previous estimate based upon observations with carotid sinus nerve stimulation during right atrial pacing in subjects with coronary heart disease $\mathrm{e}^{[8]}$. However, this value seems to be longer than the estimated $0.5 \mathrm{~s}$ latency for baroreflex modulation of the sinus rate ${ }^{[25,26]}$. It is unknown whether the observed latency was affected by the hypertension.

\section{BAROREFLEX FEEDBACK ON ATRIOVENTRICULAR CONDUCTION}

The SAC of the RR-intervals indicates that there is no relation between successive RRintervals.

We recently found non-random ventricular rhythms in horses with atrial fibrillation and RR-intervals of up to $5 \mathrm{~s}^{[27]}$. The oscillatory character of the ventricular rhythm in the horse was compatible with a baroreflex feedback mechanism, because one very long RR-interval which was associated with a major decrease in arterial pressure was followed by several short RRintervals associated with an increase in arterial pressure, which in turn was followed by one very long interval, etc. Apparently, the beat-to-beat arterial pressure variation in atrial fibrillation (Fig. 1) in human patients fails to modulate atrioventricular conduction, possibly because the mean duration of the RR-intervals is short in relation to the latency of the response. This may explain why in human patients with atrial fibrillation a baroreflex feedback on atrioventricular conduction can not be observed.

\section{EXCEPTIONS TO RANDOM NATURE OF THE VENTRICULAR RHYTHM}

The present observations are largely consistent with the earlier inference $e^{[10,22,28]}$ that in atrial fibrillation the role of the atrioventricular node is limited to scaling down the number of randomly spaced impulses that eventually reach the ventricles. However, there seem to be two exceptions. First, if exceedingly long RR-intervals, as in the horse, would occur, rhythm induced arterial pressure changes may modulate atrioventricular conduction and hence the rhythm ${ }^{[27]}$. Second, if very short RR-intervals occur, adjacent intervals may be weakly correlated (Figs 2 and 3), as was also . noted already in 1970 by Bootsma et al. ${ }^{[10]}$ in man during exercise and by Billette et al. ${ }^{[22]}$ in anaesthetized dogs with a high mean ventricular rate. We did not observe this in the $\operatorname{dog}^{[28]}$. This finding requires further investigation but it may be related to the time-constant or 'memory' of the AV conduction system ${ }^{[29,30]}$, which in cases of high ventricular rates exceeds the duration of a number of successive intervals between conducted impulses.

The assistance of Drs J. Wagner, J. M. Karemaker and A. J. Dunning is gratefully acknowledged. We thank Mrs W. van Eijsden for typing the manuscript.

\section{References}

[1] Brest AN, Wiener L, Bachrach B. Bilateral carotid sinus nerve stimulation in the treatment of hypertension. Am J Cardiol 1972; 29: 821-5.

[2] Dunning AJ. Electrostimulation of the carotid sinus nerve in angina pectoris. Amsterdam: Excerpta Medica, $1971 ; 84-8$.

[3] Epstein SE, Beiser GD, Goldstein RE et al. Treatment of angina pectoris by electrical stimulation of the carotid-sinus nerves. N. Engl J Med 1969; 280: 971-8.

[4] Braunwald E, Sobel BE, Braunwald NS. Treatment of paroxysmal supraventricular tachycardia by electrical stimulation of the carotid sinus nerves. N Engl J Med 1969; 281: 885-7.

[5] MacKenzie J. Diseases of the heart (3rd edition). London: Oxford Medical Publications, 1914; 211-36.

[6] Meijler FL. Atrial fibrillation: A new look at an old arrhythmia. J Am Coll Cardiol 1983; 2: 391-3.

[7] Borst C, Karemaker JM, Bouman LN, Dunning AJ, Schopman FJG. Optimal frequency of carotid sinus nerve stimulation in treatment of angina pectoris. Cardiovasc Res 1974; 8: 674-80. 
[8] Borst C, Karemaker JM, Dunning AJ. Prolongation of atrioventricular conduction time by electrical stimulation of the carotid sinus nerves in man. Circulation $1982 ; 65 ; 432-4$.

[9] Borst C, Karemaker JM, Dunning AJ, Bouman LN, Wagner J. Frequency limitation in the human baroreceptor reflex. J Auton Nerv Syst 1983; 9: 381-97.

[10] Bootsma BK, Hoelen AJ, Strackee J, Meijler FL. Analysis of RR intervals in patients with atrial fibrillation at rest and during exercise. Circulation 1970; 41: $783-94$.

[11] Spear JF, Moore EN. Influence of brief vagal and stellate nerve stimulation on pacemaker activity and conduction within the atrioventricular conduction system of the dog. Circ Res 1973; 32: 27-41.

[12] Mancia G, Bonazzi O, Ferrari A, Gardumi M, Gregorini L, Perondi R. Baroreceptor control of atrioventricular conduction in man. Circ Res 1979; 44: 752-8.

[13] Lau SH, Damato AN, Berkowitz WD, Patton RD. A study of atrioventricular conduction in atrial fibrillation and flutter in man using His bundle recordings. Circulation 1969; 40: 71-8.

[14] Levy MN, Martin PJ. Neural control of the heart. In: Berne RM, Sperelakis N, Geiger SR, eds. Handbook of physiology, section 2: The cardiovascular system, vol. I: The heart. Bethesda, MD: American Physiological Society, 1979: 581-620.

[15] Goodman DJ, Rossen RM, Cannom DS, Rider AK, Harrison DC. Effect of digoxin on atrioventricular conduction. Studies in patients with and without cardiac autonomic innervation. Circulation 1975; 51: 251-6.

[16] Quest JA, Gillis RA. Carotid sinus reflex changes produced by digitalis. J Pharmacol Exp Ther 1971; 177: 650-61.

[17] Ferrari A, Bonazzi O, Gregorini L, Gardumi M, Perondi R, Mancia G. Modification of the baroreceptor control of atrio-ventricular conduction induced by digitalis in man. Cardiov Res 1983; 17: 633-41.

[18] Billette J, Nadeau RA, Roberge F. Relation between the minimum RR interval during atrial fibrillation and the functional refractory period of the AV junction. Cardiovasc Res 1974; 8: 347-51.

[19] Reiffel JA, Bigger JT, Cramer M. Effects of digoxin on sinus nodal function before and after vagal blockade in patients with sinus nodal dysfunction. Am J Cardiol 1979; 43: 983-9.

[20] Hoffman BF, Bigger JT. Digitalis and allied cardiac glycosides. In: Gilman AG, Goodman LS, Gilman A, eds. The pharmacological basis of therapeutics (6th edition). New York: MacMillan, 1980; 729-60.

[21] Meijler FL, Van der Tweel I, Herbschleb JN, Heethaar RM, Borst C. Lessons from comparative studies of atrial fibrillation in dog, man and horse. In: Zipes DP, Jalife J, eds. Cardiac electrophysiology and arrhythmias. New York: Grune and Stratton, 1984; in press.

[22] Billette J, Roberge FA, Nadeau RA. Roles of the AV junction in determining the ventricular response to atrial fibrillation. Can J Physiol Pharmacol 1975; 53: 575-85.

[23] Schamroth L. Immediate effects of intravenous verapamil on atrial fibrillation. Cardiovasc Res 1971; 5: 419-24.

[24] Schamroth L, Antman EM. Calcium channel blocking agents in the treatment of cardiac arrhythmias. In: Stone PH, Antman EM, eds. Calcium channel blocking agents in the treatment of cardiovascular disorders. Mount Kisco, NY: Future Publishing Company, 1983; 347-69.

[25] Pickering TG, Davies J. Estimation of the conduction time of the baroreceptor-cardiac reflex in man. Cardiov Res 1973; 7: 213-9.

[26] Borst C, Karemaker JM. Time delays in the human baroreceptor reflex. J Auton Nerv Syst 1983; 9: 399-409.

[27] Meijler FL, Kroneman J, Tweel I van der, Herbschleb JN, Heethaar RM, Borst C. Non-random ventricular rhythm in horses with atrial fibrillation and its significance for human patients. J Am Coll Cardiol 1984; 4: 316-23.

[28] Strackee J, Hoelen AJ, Zimmerman ANE, Meijler FL. Artificial atrial fibrillation in the dog; an artifact? Circ Res 1971; 28: 441-5.

[29] Billette J. Short time constant for rate-dependent changes of atrio-ventricular conduction in dogs. Am J Physiol (Heart Circ Physiol) 1981; 241(10): H26-33.

[30] Harms FMA, Heethaar RM, Robles de Medina EO, Meijler FL. Atrioventricular nodal 'memory' studied by random atrial stimulation. Am J Cardiol 1980; 59: 459 (abstr). 